\title{
1. Introduction: energy culture in an age of transformation
}

\subsection{INTRODUCTION: THE PRODUCTION OF ENERGY CULTURE}

Energy creates material well-being for society. Energy is hot food on the table, a warm home, and a job. Modern societies require the state to deliver a functional, efficient, and sustainable energy system. There is an inherent tension with the state pushing to meet social demands and guide industry to deliver economic growth. Eastern Europe provides a good example of when social demands align with political and economic change. After 1989, the collapse of the USSR and later membership in the European Union, changed social policies and how citizens were able to put food on their tables. For the low-carbon energy transition, it is important to understand this previous round of state-social change. The reason for this is that the energy system in the region exposes ongoing political, economic, and social pressures to build a more just and sustainable way of life.

Current European Union effort for net-zero carbon emissions by 2050 is ambitious for including society, industry, and governments in the ongoing energy transition. Likewise, specific policies like a 'just energy transitions' supported by the EU (European Commission 2020) demonstrate the political importance of building an equitable energy system. Fostering the technical transition away from fossil fuels to renewable energy technologies involves energy policies rooted in social engagement. The task of this book is to understand how energy transitions occur at different scales and deliver a just energy transition for society in three Eastern European countries: Hungary, Lithuania, and Poland. Developed here is an 'energy cultures' framework showing how cultural struggles create power relations with the winners choosing the energy resources and technologies of the future. This contribution provides an effective lens to understand whether Europe is rolling out a just transition or simply extending current political and economic arrangements.

At the turn of the twentieth century, scholars also sought to make sense of their rapidly changing energy system and the social implications. The study of 'energetics' sought to explain the rapid industrialization of countries and the 
role of society in the technological transformation (Stewart 2014). This view relied on a positivist socio-cultural perspective, which highlighted efficiencies created through rational choices. An 'efficiency culture' was viewed as essential to increase savings in the energy system and thereby benefitting society. Likewise, efforts to mitigate climate change revolve around changing the efficiency of society and technologies in the energy system.

Identifying who is responsible for improving technologies and practices is essential to affect systemic change. In 1908, physicist and Nobel laureate turned sociologist, Wilhelm Ostwald outlined how it was only humans that could use fire to transform inorganic matter into material well-being (Ostwald 1907, in Stewart 2014). Ostwald identified a broader social responsibility when he wrote that, "The general task of culture as a whole consists in ensuring the most favorable transformation" of energy (Stewart 2014, 344). Through this view of culture and efficiencies, mechanical engineers to diplomats hold a responsibility to lower the cost of energy for the "working classes" at all stages of the energy system (Stewart 2014, 344). While this may be interpreted as a bourgeoisie perspective, it underscores the importance of society and individuals working together to lower costs and increase efficiency along with reducing waste. The study of energy cultures identifies social and individual actions as contributing towards a more efficient and socially just energy system.

Culture provides a means to understand how society utilizes the energy system for its material well-being. Digging deeper into cultural connections in the energy system, Ostwald did not develop this concept in isolation. Geographer Friedrich Ratzel and others at the Leipzig School of Cultural Sciences also influenced Ostwald's theoretical development; with Ostwald giving an inaugural address in 1887 on 'Energy and its Transformations' (Stewart 2014, 334). While sociologist Max Weber criticized the attempt of a physicist to inform those in the "sciences of culture" (Weber, Mikkelsen, and Schwartz 1984, 51), Ostwald, nonetheless, abstracts the production of energy into the 'production of culture' by framing access to the energy system as a reflection of individual and social actions creating material well-being. In contrast, the failure to develop material well-being reflects the failure of society and individuals to operate in an equitable energy culture. The study of 'energy cultures' exposes the relational struggles of individuals and society producing a socially just energy system.

This perspective of cultural struggles fosters an understanding that culture emerges by contestation. Culture created from contestation enables the expression of differences within and between different groups (Mitchell 2000). Despite 'difference' highlighting what culture is, defining culture remains difficult. Cultural Geographer, Donald Mitchell identifies five ways to describe 'culture', from patterns of people to a looped 'culture-making-culture' and 
ending with "culture is everything" (Mitchell 1995, 104-5). An anthropological perspective sees culture as a scaffolding providing structure to meanings people experience (Geertz 1973, 312). A sociology perspective asserts social practice creating cultures (Giddens 1982). In short, culture is a description of social interactions, but lacking a 'definable definition'.

If culture cannot be defined, then what is culture? Clearly, culture is also not benign. Culture is an active political and economic tool that can control and influence the material well-being of society. Mitchell explores how culture represents the expression of power, rather than just how people live. Through this lens, it is the relationship between social groupings that produces culture (Mitchell 2000, 73).

My argument is that it is in the interaction - the struggle - between the production of 'culture' and its use that 'culture' is produced, not as a thing, but as a relationship. So when I ask who produced culture, I always turn to the study of relationships; when I ask why it is produced, I turn to questions of power. (Mitchell 2000, xviii)

Culture is politics, culture is power, and culture is relationships. Social practices, perceived through cultural representations, such as cars or cooking fires, also represent power relationships of resource access or affordability. These relationships emerge through relational struggles at a range of scales, whether in the international or local community. Power relations influence the material well-being of society and access to energy.

The importance of Ostwald's energetics perspective is in the conversion of resources through interactions, such as social, technical, and physical. Rather than defining energy culture, we can describe it as: Energy cultures are the social and physical interactions forming relations in the energy system, extending from resource extraction through technologies of conversion, combustion, and networks, providing for society's material and physical well-being. Understanding interactive relationships around the point of 'combustion' is essential in the modern energy system because it underlies our modern efforts to address climate change.

The point of combustion turns out to be the central point to examine the Anthropocene. As Dalby points out, the examination of "combustion and fire ... bridges the divides between human and physical sciences, and as such offers a way for linking traditional social science discussions of geopolitics with the forcing mechanisms that are driving biosphere change," of the Anthropocene (Dalby 2018, 720). One hundred years ago, Ostwald grasped the point of conversion as linking these broader social and physical systems. A physicist turned sociologist, he was able to grasp the conversion point of resources and social interaction in an economic order that also applies to our present environmental and energy challenges. Energy cultures provide a means to understand the 
power relations meeting at the point of combustion within the broader energy system. The conversion from resources to material and emotional well-being is where energy cultures expose embedded power relations.

This chapter quickly engages in the question of how to define energy cultures and expose the power relations. This is done in the next section by developing a set of axioms to explain, rather than define culture. Section 1.3 reviews existing energy culture literature and identifies the inability to more explicitly understand power relations within culture and how these shape energy practices. Section 1.4 extends this literature review to outline the importance of cultural relations as essential components to the energy system. The task in section 1.5 is to deconstruct the energy system into a physical and social energy system which is proposed as a means to differentiate between more explicit uses of energy in the form of artifacts or seen on the landscape, contrasting with a more implicit understanding of deep power structures shaping the way society interacts with the energy system. Section 1.6 provides further framing of the role of energy justice and geopolitics to conceptualize and understand how culture is created through relational struggles at both the domestic and international scales. Likewise, section 1.7 outlines the ontological framings and epistemological perspectives on the energy system which provide the necessary tools to deconstruct and construct a cultural representation of culture. Application of the theoretical construct of energy cultures is introduced to the case studies in section 1.8 while section 1.9 provides the outline of the book and the perception of how energy cultures construct the energy system.

\subsection{ENERGY RELATIONS: AXIOMS OF ENERGY CULTURES}

Since culture cannot be defined, then a set of axioms provides the means to explore what is energy culture. Three axioms serve as a guide to energy cultures jostling around the conversion point. These axioms provide a means to structure the analysis and understand how energy cultures, and the embedded power relations, work to convert resources into material well-being for society. Their development is based on a set of four criteria developed by Heinberg, originally in relation to refining the concept of 'sustainability' into a set of "self-evident truths" (Heinberg 2010): 
a. To qualify as an axiom, a statement must be capable of being tested using the methodology of science.

b. Collectively, a set of axioms intended to define sustainability must be minimal (with no redundancies).

c. At the same time, the axioms must be sufficient, leaving no glaring loopholes.

d. The axioms should be worded in terms a layperson can understand. (Heinberg 2010, 15)

In a similar spirit of guidance, in the area of energy and climate change, Sovacool and Brown develop six maxims to structure effective energy analysis (Sovacool and Brown 2015). These are more value laden and meant to guide decisions that are "ethical or at least informed" (Sovacool and Brown 2015, 41). But they are meant to spur improvement in the daily actions of researchers and policy makers. From this viewpoint of axioms and maxims, it is useful to introduce into energy cultures a set of axioms that assist in identifying both the representation of culture and the methods of cultural (re)production, thereby avoiding an epistemological trap of defining what culture is. Rather, three axioms describe through a set of "self-evident truths" (Heinberg 2010), what energy cultures are and how they are produced:

1. Energy cultures are spatial expressions of the social milieu around energy systems and perceived through physical expressions of artifacts, imaginaries, and inequality of material and environmental differences.

2. Energy cultures play out at different scales and are both socially and economically transformative and reliant on power relations between scales.

3. Energy cultures are relationally transformative in energy systems, including mechanical and thermal, social, political and economic.

Framing the axioms is the role of the state. The state is essential in the creation of energy cultures. The interlinkage between state and society is connected through industrialization within national boundaries. For the energy sector, the built energy system is reliant on the government regulation of the utility sector, which supplies services to industry and households. An historical perspective frames both Ostwald's observation on the modern energy system delivering material benefits to society (Stewart 2014, 344), and the rise of the sovereign state assisted by industrialization (Knutsen 1992, 128-9). The state, society, and industry interlink to create unique national energy cultures based on a social pact.

The growth of utilities, and their economic and social importance, became central in the daily life of society and industry. The dramatic impact of the Great Depression, initially triggered by utilities' financial accounting tricks, 
required government intervention to either take over ownership or to administer regulatory oversight of activities (Hirsh 1999). In an energy system with government regulation, there emerges an informal 'regulatory compact,' which allows utilities to operate for the public good. Society and industry benefit from a coordinated utility sector with shared infrastructure and long-term technological renewal. Energy companies may be privately or publicly owned, but the global rise of National Regulatory Agencies (NRAs) since the 1990s corresponds with the liberalization of electricity and gas markets across the globe. The universal regulatory compact cements government oversight of the utility sector.

The concept of the regulatory compact extends back to English Common law in the sixteenth century. At this time, franchises were issued for 'common calling,' monopolies granted in exchange for providing goods and services at reasonable rates, such as ferry boats, highway operators, and wharves (Hirsh 1999, 15-18). In 1903, the US Supreme Court used the term 'public utilities' to describe monopolies operating in the public good (Hirsh 1999, 15-18). The right of the state to regulate public utilities is seen through an 'institutionalist' perspective utilizing "regulation as an instrument of social control" (Hirsh $1999,18)$. That is, industry - or the energy sector - is regulated for the social good. In a 'regulatory compact' form of governance, society gives the state the right to regulate utilities. This means there is coordination in the energy system to ensure the use of a single network and consumers benefit by lower costs due to greater coordination or minimalizing competition in specific areas.

The regulatory compact focused on state-industrial relations, likewise, state and society were bound in a social contract. The sovereign state held power given to it by society. From an Enlightenment viewpoint Vatn outlines how individuals and the state develop a social contract, which through a Hobbesian perspective, "give away some of their freedom to the sovereign whose assignment is to secure order" (Vatn 2005, 26). That is, people entrust their freedom to the state to more efficiently provide protection. This understanding stems from how people exist in a 'state of nature,' which is characterized 'by universal values of freedom and equality. People are, according to [John] Locke, 'born' with a sense of equality and freedom, and the state is foremost an articulation of these human values or human rights" (Vatn 2005, 28). The authority of the state, and society's expectation, rests on this transfer of freedom to the state and in turn the provision of equality and freedom. Therefore, there is a social contract between individuals of and the state to build and maintain utilities for the public good.

Over time, an equitable and secure energy system is built to serve society and industry. State institutions, therefore, are essential managers of energy services and resources. From a functional standpoint, the social contract is translated into political activity, where politicians are responsible for ensuring 
energy services meet the needs of the people. Universal access to energy is a modern fulfillment of the social compact between the state and society. "Alleviation [of energy poverty] is a fundamental political duty rather than simply an optional act of benevolence" (cf. de Vita 2007; Bouzarovski and Simcock 2017, 645). Thus, the social pact is fulfilled by political action mobilizing state institutions to deliver (and ensure) delivery of energy services. The public service of politicians requires them to ensure the protection of "universal values of freedom and equality" (Vatn 2005, 28), reflecting obligations of the modern state under both the ancient social contract and the modern regulatory compact. The state is authorized, by society, to act both internationally and domestically to secure a modern energy system to ensure universal access to energy services and resources.

The state holds the ultimate responsibility to organize the energy system, but there remain fundamental political, social, and philosophical trade-offs that ensure perpetual tension and injustices within the system. Delivery, affordability, and accessibility to energy services require a balancing of rights. Negligence in one area may be a product of action in another area:

Energy systems can be reconceived as a political, deliberative challenge involving the satisfaction of competing preferences; a social dilemma pitting, at times, the climatic and development goals of energy security or improved resilience against the pressing needs of marginalized and vulnerable populations; and a moral quandary revolving around how energy burdens and benefits are fairly, or unfairly, disseminated. (Sovacool et al. 2017, 689)

The investigation of tensions within the social compact and how governments organize the energy systems requires a broader picture of policy and security choices, along with moral quandaries. Utilizing 'culture' as a conceptual framing of relational struggles around justice and security within the energy system provides a means to understand power relations enabling or preventing access to energy resources and services. More specifically, an energy cultures approach utilizes the academic framing of energy justice to provide a whole systems approach at different scales of the energy system. "At each stage of the energy system - resource mining or energy production, for example - energy justice can engage with local, regional and national justice questions" (Jenkins 2018, 119). Energy justice goes beyond cost-benefit analysis and engineering projects; energy systems "are about political power, social cohesion, and even ethical and moral concerns over equity, due process and justice" (Sovacool et al. 2016, 5). Energy justice provides a geographic perspective on 'bounding out' scales of activities around justice occurring within the energy system, such as identifying local, regional, and national processes (Jenkins 2018, 120).

Geography and politics are bound up in the energy system. Therefore, understanding international political economy is essential for understanding 
how the state ensures the delivery of resources and the continued operation of its domestic energy system. Geopolitics is essential to understand how international political actions influence and are influenced by domestic energy cultures. "A culturally informed political geography is about identifying and showing the mutually constitutive effects of cultural signs and symbols, on the one hand, and political acts, on the other" (Toal and Agnew 2002, 456). This reading, influenced by societal norms, values, and the physical barriers surrounding a state, produces new critical geopolitics of culture (O Tuathail and Agnew 1992). Rather than geopolitics describing a clash of nationalistic imperialist interests, geopolitics reflects cultural struggles influencing each nation-state's social and political practices.

The conceptual framing by geopolitics and justice provides a multi-paradigm approach (Burrell and Morgan 1979; Gioia and Pitre 1990; Sovacool and Hess 2017) to energy cultures. This paradigm approach contributes both a subjective and objective perspective: geopolitics of cultures (subjective) and an energy justice (objective) bridge ontological divisions within an energy culture concept. Geopolitics and justice contain the tools to expose and assess a continuum of international and domestic power structures within the energy system. Energy cultures, as a conceptual framing, provide the means to bridge the local/international dichotomy and the supply/demand sides of the energy system. The global security apparatus of the state serves to secure resources to meet the cultural energy practices of industry and households. Political leaders exert their power by delivering on the social contract and regulatory pact of the modern state. Energy cultures are diverse; discussed next is how the energy cultures literature spans both domestic and international contexts, which account for both the supply and demand sides of the energy system.

\subsection{ENERGY CULTURE LITERATURE}

The term 'energy culture' already benefits from a diverse set of research identifying the role of culture in the energy system. Current efforts explain alterations and orientations of energy systems and use culture as a broad explanatory device that reflects a cohesion and division within society over material and social practices within the energy system (Stephenson et al. 2010; Sheller 2014; Sovacool 2016; Rosicki 2017). Their strength is exposing social unity or difference; however, their weakness is providing a critical examination of how culture is created and how power relations influence and orientate the trajectory of energy systems. The existing terminology of 'energy culture' focuses on the interactive consumer behaviors of "cognitive norms, material culture, and energy practices" (Stephenson et al. 2010, 6125) or broadly applied to the socio-economic change in the second industrial revolution (Sheller 2014). The literature provides a means to both understand explicit 
cultural representations, such as signs and symbols, or implicit socio-political and economic interactions.

This review of energy cultures literature will use an 'explicit' and an 'implicit' categorization of approaches. This enables a more precise means to capture the powerful role culture holds in societal values and norms within the energy system. Energy culture is more than a descriptive device of social interactions; it is a powerful expression and tool of authority, affecting public access to resources and technologies. Culture is both seen and hidden. Implicit energy culture is the expression of power relations within an energy system, such as rules, regulations, values, and access. Explicit energy culture is the expression of materiality seen on the landscape through forms such as infrastructure and poverty. Culture emerges as the expression of social and economic value (Mitchell 2000), while within the state-controlled energy system, political authority influences the structure of economic and social activities. This political influence includes the cultural orientation of the energy system towards different types of configurations, reflecting implicit social values, explicit built and natural environmental factors, and historical geopolitical alignments. The political system emerges as a central component to direct both the explicit and implicit orientation of the energy system. The term 'energy system' therefore refers to the politically influenced physical and social components that comprise the material and social practices around the combustion of energy resources.

\subsubsection{Explicit energy culture: assembling practices of culture}

Explicit energy culture focuses on material practices of society embedded in the physical energy system. The reconfiguration of an energy system and the resulting cultural transition is outlined by Ruotsalainen et al. They assess a 'peer-to-peer' future where "self-organizing citizens" are empowered by "automation, ubiquitous digital communications" and declining costs of energy, living, and production (Ruotsalainen et al. 2017, 237). Despite using the term 'energy culture,' the authors avoid explaining what energy culture is. This article is representative of other articles discussed. There is an implicit assumption that the reader accepts there is an energy culture formed through the interaction of technology and social relations; however, there is no explanation as to what creates an energy culture.

In a similar explicit exploration of energy culture, but with more exceptional care of context, cultural barriers to energy efficiency stymie the uptake of clean energy solutions in the US (Sovacool 2009). The abundance of resources led Americans to celebrate "sheer abundance and limitless consumption" (Sovacool 2009, 370). Culture for Sovacool is rooted in the industrial and resource history, including the engagement of people with the land, which 


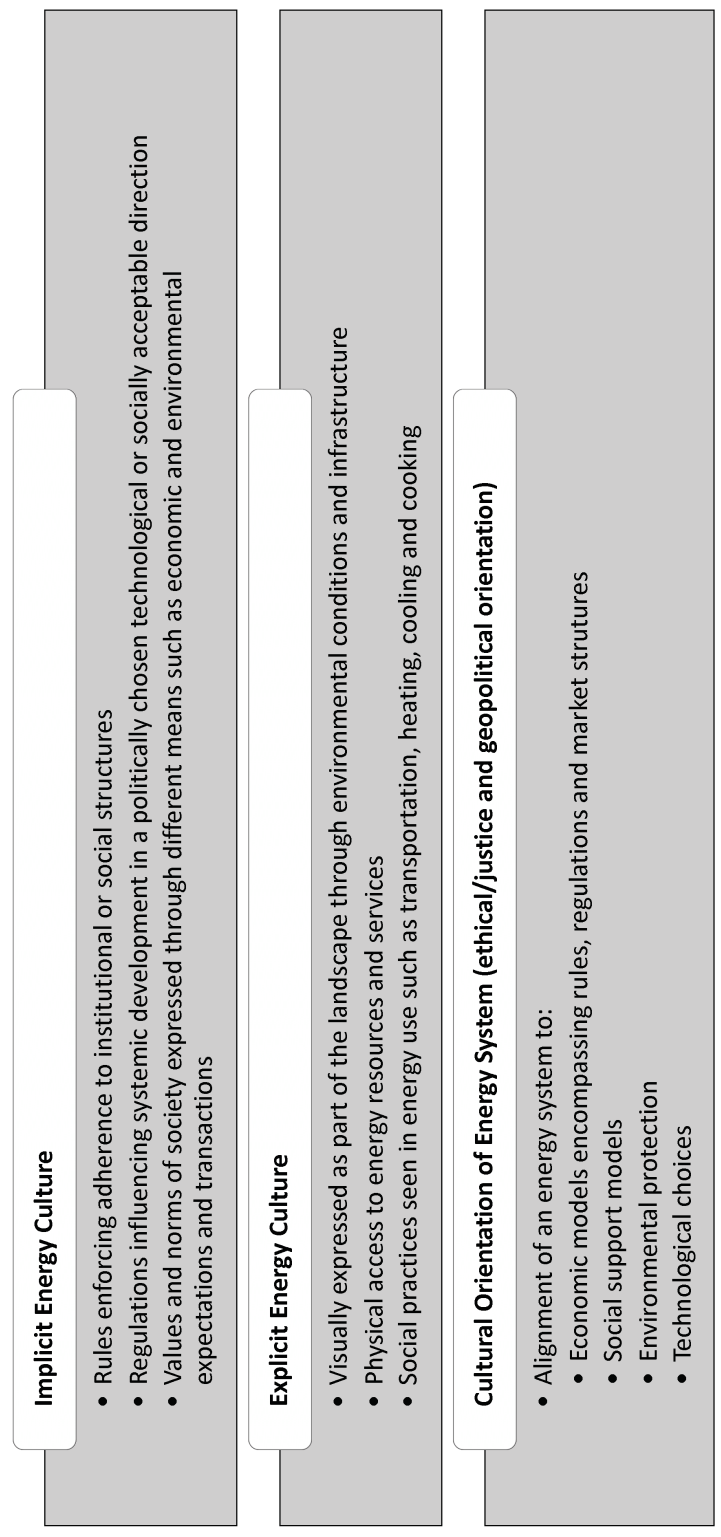


ultimately results in the celebration of abundance and high energy consumption. However, here as well, energy culture is described without fully setting up what culture is or how it is created. It is representative of energy culture existing in energy transitions, without a critical engagement with interactions that shape culture.

Extending this explicit label of energy culture is the literature using the previously developed Energy Cultures Framework, containing three core elements of (1) material culture; (2) practices; and (3) norms. The framing assists in understanding practices around fuel poverty, buying habits, and generational energy choices (Stephenson et al. 2010; Stephenson 2018). A description of the application of energy culture demonstrates institutional processes fostering a particular energy culture, which resists change to using energy-saving LEDs (Dew, Aten, and Ferrer 2017).

The study identified how shipboard technologies, practices and norms came together to form a naval energy culture that was impervious to change, and reinforced by external influences such as congressional appropriation processes, qualified supplier bases and executive actions of the federal government. (Stephenson 2018, 244)

The energy cultures framework draws from Actor-Network Theory (ANT), which explains scientific or technical artifacts' integration into social relations. "technological change is the product of complex relations of alliance and conflict among divergent actors and their interests" (Sovacool and Hess 2017, 720). The Energy Cultures Framework considers the broader energy system with individual behavior at the center. It explores outward aspects of the system which strongly influence behavior, then finds what interventions can change behavior (Stephenson et al. 2010, 6121). This framework serves as a conceptual way to understand influences on consumer actions to prompt change to lower consumption practices or technologies. The concept has been extended to include practice theories application to a sustainability cultures concept (Stephenson 2018). The limitation (which is also its strength) lies with the focus on behavior and networks within specific systems of alliances of actors; by design it neglects larger state power relations, geography, and supply-side political actions - essential elements to understanding historical epochs of energy transitions impact on socio-political (cultural) perspectives.

A final noticeable use of explicit 'energy culture' is a socio-technological perspective provided by Sheller. Energy culture draws on the "circulation of energy" to describe "how built forms and material assemblage" develop ways of life around energy consumption practices, while also perpetuating "particular energy use patterns" (Sheller 2014, 128-9). The interaction between material and life practices perpetuates particular energy regimes (similar to Sovacool's framing). Using this approach, the energy culture around the global 
aluminum industry is examined, exposing subjective and socio-ecological experiences wrapped in energy transitions. The explicit use of the term 'energy culture' provides a means to frame material practices in society. This approach fits well with a neo-Marxist perspective that will be described below to understand the use-value between relations in energy systems. First, as the next section describes, it is essential to understand how narratives and stories are created around energy relations.

\subsubsection{Implicit energy culture: expressing relations through narratives and stories}

The implicit existence of energy culture as a social construct emerges through a descriptive approach of energy relations. A critical reading of energy transitions can expose energy cultures in a range of formats. The book, Total Transition: The Human Side of the Renewable Energy Revolution (Pai and Carr-Wilson 2018) is a narrative travelogue of two students researching energy transitions by comparing locations in Canada and India. Extraction of coal in India is contrasted with the extraction of tar sands in Canada. The result is a surprising parallel of experiences and yearning for clean energy transitions from both Indians and Canadians, with individuals literally sickened by fossil fuels.

As described from an excerpt on living with coal in India:

Sandeeep asked Suresh how his house flooded and where he lives now. Suresh explained as he continued to brush water from the house. "The underground fires burnt the coal lying below my house, the land subsided, and the level of my house went below the level of the pond." Since Suresh's house had no doors, water from the pond had an easy ride into the house. (Pai and Carr-Wilson 2018, Loc. 996)

As described from an excerpt on living with the oil sands in Canada:

We had smelled a strong chemical odor when driving into town, and asked them to tell us about the air. "You've got to be tough to live here!" Harvey exclaimed. "The air will kill you in no time. We're right in the middle of the oil sands." (Pai and Carr-Wilson 2018, Loc. 1354)

By writing the book in a travelogue format, cultures are explored along with the impact of corporations and government decisions on the environment and human life. The authors themselves (students of this author), were steeped in energy transitions literature during their university education. Therefore, it is interesting that these scholars used narrative to describe their own and others' lived experiences of energy transitions. The power of stories to communicate 
energy transitions provides perspectives missed by more formal framing of energy transitions.

Stories are used to communicate with, influence, and engage audiences; they serve as artefacts to be investigated in terms of content, actors, relationships, power, and structure; they can be used to gather information, provide insight, and reframe evidence in ways that more science-ordered formats miss. But they are not benign or neutral ... . (Moezzi, Janda, and Rotmann 2017, 1)

Creating a "purposeful cultural turn" on climate change and uncovering cultural influences draws in cultural interpretation in the arts and humanities (Smith et al. 2017, 287), demonstrating how people's lives and their landscapes influence perceptions of energy transitions. Assessing these perceptions requires both a top-down and bottom-up methodological approach. The top-down perspective given by the energy trilemma politically constructs notions of energy poverty (Cloke, Mohr, and Brown 2017). The description emerges that socio-technical imaginaries influence development of energy policies and systems, thereby affecting the interpretation of what energy poverty is. By shaping energy discourses, energy transitions are given a direction which is driven by the top (or elites) (Cloke, Mohr, and Brown 2017, 264), negating more social influences on how an energy transition should occur that accounts for those living in energy poverty. The example above provided by Pai and Carr-Wilson of a bottom-up perspective gives context to the socio-cultural lived experiences enabling an effective method accounting for the economic and technical barriers to energy transitions (Cloke, Mohr, and Brown 2017, 263-4).

Reading about 'energy cultures' on the landscape or through stories exposes energy lifestyles that more rigid theoretical literature misses. Symbolic actions expose social practices between people and between communities and the landscape. At the material level, then, "It is about seeing pipelines as cultural objects" (Macdonald 2017, 39). The literature around 'petrocultures' deploys this humanistic method to understanding relations within a petroleum energy system (Wilson, Carlson, and Szeman 2017). These methods expose the "oil-reliant capitalism seeking to extend and perpetuate supply while downplaying the ongoing, exploitative shame of extraction" (Macdonald 2017, 39). 'Reading' energy requires both implicit and explicit examination of cultural interactions within the energy system.

Explicit and implicit uses of energy culture demonstrate both the diversity and variety of examples involving culture in energy transitions. From the geopolitical and security perspective to stories of the everyday lives of people living with pollution or in energy poverty. The above descriptive analysis captures a range of approaches to describe a culture in energy transitions. 
However, the diversity of approaches to energy culture neglects a more critical reading that deconstructs culture in terms of power relations and who is creating culture. The next section provides a means to deconstruct and identify different paradigms of culture within the energy system and within the energy transitions literature.

\subsection{LITERATURE REVIEW: CURRENT WEAKNESSES OF ENERGY TRANSITIONS LITERATURE}

The energy culture literature is broadly placed within an energy transitions framing. There are descriptions of how people interact with each other or with the built environment. However, to make a conceptual framing of energy cultures requires going deeper to understand how culture is created and who creates culture. Therefore, a more in-depth understanding of the paradigms of theories is necessary. By identifying who creates culture, my purpose is to empower researchers with a conceptual tool to expose power relations in order to foster change. Conceptually, exposing power relations can lead to a more equitable and just energy system. However, 'justice for whom?' is also questioned (see Sovacool et al. 2019, 214). In an era with the slogan 'just energy transition' being adopted by the EU (European Commission 2020) and others (McCauley and Heffron 2018), questioning what justice is and who decides is even more relevant.

Energy transitions literature creates boundaries of ordered frames of perceptions (Geels 2010). These break down energy transitions into ordered frames of politics, technology, society, and a range of other processes - thereby fracturing the ability to understand power relations within the whole energy system. A cultural approach to energy, in contrast, provides a holistic approach to understanding power relations within the energy system. This matches the call by energy justice scholars for a more holistic perspective of the energy system (Jenkins 2018; McCauley and Heffron 2018; Sovacool et al. 2016; Goldthau and Sovacool 2012).

The development of nested frameworks to conceptualize the energy system by Cherp et al. provides the context to understand the divisions within current theoretical approaches. This approach encompasses a multitude of frames into a meta-theoretical perspective: interlinking the puzzle pieces of an energy system into a dynamic transition process becomes daunting. "One diffculty in explaining energy transitions is the disciplinary diversity of required scholarly approaches. Existing reviews of the vast transition literature identify relevant knowledge from economics, sociology of technology, political science, geography, history and other disciplines" (Cherp et al. 2018, 175). The task in this section is to establish the limits and boundaries of existing frameworks and 
paradigms, thereby enabling bridges between the conceptual fissures of the energy system.

\subsubsection{Missing culture}

The conditions for energy technologies to grow or decline are dependent on the socio-political relationship. Innovation is critical, as the above theories identify; it is also wrapped up in cultural influences. However, within energy transition literature, culture is marginal, and instead the focus resides with structural forces, such as controlling 'regimes' (Turnheim and Geels 2013), 'carbon lock-in' perpetuated by institutional complexes (Unruh 2000), or perceptions and interactions of actors through imaginaries of the nation or society (Kuchler and Bridge 2018), or actions of entrepreneurship and innovation (Seyfang and Smith 2007; Kivimaa and Kern 2016). Transition literature places the control of technology within structured frames of regimes and imagined perceptions that fail to engage with the source of either who creates the structure or who controls the perceptions of the structures.

In a review of energy transitions literature, Sovacool and Hess provide a wide-ranging assessment of theoretical approaches. They identify 96 theories and approaches to describe energy transitions (Sovacool and Hess 2017). Despite the diversity, the limitations of some of the most popular result in the inability to explain socio-political action inhibiting the choice of technology. Instead, the approaches emphasize the driving inertia of technology to force social and political change. Within this book, culture is perceived to be the vehicle driving or preventing technological change. The role of culture in energy transitions is clear. For example, Kuchler and Bridge provide an apt observation of the outcome of culture. "During this time the slogan 'Poland stands on coal' derived its shared meaning and cultural power by mobilising several of coal's distinctive material properties" (Kuchler and Bridge 2018, 144, emphasis added). The result of cultural mobilization is displayed. But to understand how culture reflects power relations, then a more in-depth examination needs to pay attention to what culture is, or who is controlling or influencing culture.

Culture slips through the energy transitions literature, despite its undeniable presence. The term 'culture' is 'downgraded' to a fuzzy "topical focus" (Sovacool and Hess 2017, 735), which demonstrates both the unwieldy broad nature, but also the importance to understand why it appears so unbounded by modern conceptual framings. Table 1.1 reflects the centrality of culture across theoretical approaches of energy transitions, but also the recent inability in the literature to properly label culture as a source of power within the energy system. Within the four paradigms, 'culture' resides in these four ideal types of theoretical paradigms by means of description or name, which are drawn 
from Gioia and Pitre (1990): functionalist, interpretivist, humanist, and structuralist (conflict). The categories also align with the descriptions of 'implicit and explicit' energy cultures (second half of Figure 1.1). The four paradigms provide a means to understand the energy transitions literature and how culture operates within the energy system.

\section{Table 1.1 Paradigms of knowledge aligned with implicit and explicit energy cultures}

\begin{tabular}{|c|c|c|c|c|}
\hline & $\begin{array}{l}\text { Functionalist- } \\
\text { Institutionalist }\end{array}$ & Interpretivist & (Radical) Humanist & $\begin{array}{l}\text { Conflict/(Radical) } \\
\text { Structuralist }\end{array}$ \\
\hline $\begin{array}{l}\text { Topical focus: } \\
\text { Sovacool and Hess } \\
(2017,735)\end{array}$ & $\begin{array}{l}\text { Norms, values, and } \\
\text { institutions }\end{array}$ & $\begin{array}{l}\text { Discourse, practice, } \\
\text { and culture }\end{array}$ & $\begin{array}{l}\text { Historical change } \\
\text { and cultural } \\
\text { difference }\end{array}$ & Societal conflict \\
\hline $\begin{array}{l}\text { Geels and Verhees } \\
(2011,912)\end{array}$ & $\begin{array}{l}\text { Culture shaping, } \\
\text { "action by defining } \\
\text { what people want } \\
\text {... Because people } \\
\text { are socialized into } \\
\text { existing values, } \\
\text { there is little space } \\
\text { for agency, freedom } \\
\text { and creativity." }\end{array}$ & $\begin{array}{l}\text { Developing agency } \\
\text { and creating } \\
\text { agency, "culture } \\
\text { thus becomes a } \\
\text { 'toolkit': actors } \\
\text { draw upon deep } \\
\text { cognitive structures } \\
\text { or 'repertoires' and } \\
\text { actively use symbols } \\
\text { and categories for } \\
\text { sensemaking." }\end{array}$ & $\begin{array}{l}\text { "Meanings that have } \\
\text { been produced do } \\
\text { not go away, but } \\
\text { provide background } \\
\text { material for the next } \\
\text { round" of social } \\
\text { construction. }\end{array}$ & $\begin{array}{l}\text { Culture as a deep } \\
\text { cognitive structure } \\
\text { that forms } \\
\text { perceptions of } \\
\text { reality and provides } \\
\text { people with } \\
\text { frames of meaning } \\
\text { prompting action; } \\
\text { however, this holds } \\
\text { elements of cultural } \\
\text { determinism and } \\
\text { neglects agency. }\end{array}$ \\
\hline $\begin{array}{l}\text { Type of energy } \\
\text { culture: }\end{array}$ & $\begin{array}{l}\text { Explicit energy } \\
\text { structure: }\end{array}$ & $\begin{array}{l}\text { Explicit energy } \\
\text { structure: }\end{array}$ & $\begin{array}{l}\text { Implicit energy } \\
\text { structure: }\end{array}$ & $\begin{array}{l}\text { Implicit energy } \\
\text { structure: }\end{array}$ \\
\hline $\begin{array}{l}\text { Implicit or Explicit } \\
\text { (see Figure 1.1) }\end{array}$ & $\begin{array}{l}\text { Socialized into } \\
\text { existing energy } \\
\text { practices. Loss/ } \\
\text { lack of agency to } \\
\text { foster change due } \\
\text { to institutional } \\
\text { structures. Labels } \\
\text { provide meaning } \\
\text { to actions, } \\
\text { including the built } \\
\text { environment and } \\
\text { landscape. }\end{array}$ & $\begin{array}{l}\text { Perceptions shape } \\
\text { and are shaped } \\
\text { by symbols and } \\
\text { physical practices. } \\
\text { Physical and social } \\
\text { access to energy } \\
\text { resources shape } \\
\text { social practices } \\
\text { within the energy } \\
\text { system. }\end{array}$ & $\begin{array}{l}\text { Active engagement } \\
\text { for placemaking. } \\
\text { Historical } \\
\text { re-narratives } \\
\text { possible, thereby } \\
\text { influencing both } \\
\text { structural forms and } \\
\text { societally contested } \\
\text { norms. }\end{array}$ & $\begin{array}{l}\text { A cosmopolitan } \\
\text { view of justice } \\
\text { drives change } \\
\text { to conform with } \\
\text { perceptions of } \\
\text { reality aligning } \\
\text { with cultural } \\
\text { interpretations of } \\
\text { equitable relations. }\end{array}$ \\
\hline
\end{tabular}

Source: Categories from Sovacool and Hess $(2017,735)$; Geels and Verhees $(2011,912)$; Gioia and Pitre (1990). 
Perceptions of energy cultures influence how energy transitions occur. Each category in Table 1.1 holds different 'paradigms of knowledge' that reflect the fundamental beliefs of the social construction of 'reality.' An example of how these different paradigms can be used is provided by Geels and Verhees (2011), who draw on these framings to understand technological change through the innovation of the Dutch nuclear energy sector. For them, 'cultural legitimacy' is essential to know where innovations may have social acceptance or rejection. Thereby cultural framings not only shape how the world (or the energy system) is viewed but what technologies are allowed into the world thus expressing a source of authoritative power from an energy culture.

More specifically, energy transition literature holds weaknesses unable to exploit the elements of culture to humanize technological trajectories. For example, in the theory of 'Sociotechnical Imaginaries' which fits within both the Interpretivist and Critical Humanist categories; this approach examines the "imagined forms of social life and social order reflected in the design and fulfillment of nation-specific scientific and/or technological projects" (Sovacool and Hess 2017, 719). That is, technological projects driven by an (innovative) scientific perspective drive forward technological change, which is 'forced upon' society. The problem with this approach is it negates the power of society to choose its technology, with elites or regimes at the center of technological change (see Unruh 2002). It is unfit to explain political and social activities and conflicts stemming from societal choices and the interaction with elites, including history and localized perspectives.

Another widely used concept is the Multilevel Perspective (MLP). This theory sits within the Functionalists-Institutionalist category and is centered on how the innovation of new technologies eventually disrupts a socio-technological regime (Geels 2002, 2010). Regimes guide innovation and diffusion of technologies resulting in a gradual or sudden change in both technology and society. The limitation of this approach is heavily on the social side because it removes agency and human need from the evolution and deployment of energy technologies (Sovacool and Hess 2017, 710-11). Socio-techno systems utilize technologies, services, and other components of the energy system to fulfill society's energy needs through a 'deep structure' or 'grammar' that organizes actions (Vinichenko 2018, 28). Despite the 'deep structure,' technology (and its innovation) remains a primary organizing mechanism. The theory cannot explain political decisions and where authority and power reside, which influence technology deployment. As will be described further below, current uses of the energy justice framework also fit into this category because of the normative and positivist labeling of perceived injustices.

Aligning with the final category of social 'Conflict' is Social Practice Theory, which focuses on behaviors "driven by beliefs, values, lifestyles, and tastes that express personal choice" but excludes explicit mention of culture 
(Sovacool and Hess 2017, 711-12). It is important not to lose culture in trying to be too precise. Culture is essential and influences and reflects both performance and interactions with technologies and material choices made by society. Thus, cultural interactions are meaningful and influence the types of technologies in use. The limitation of this approach lies with how broader systemic change and social practices are void of a strong authority taking action (Sovacool and Hess 2017, 713). In other words, Social Practice Theory accounts for culture, but is unable to account for drivers of change.

Figure 1.2 provides an overview of the paradigm axis and position of theories associated with the different quadrants. The diagram provides a description of the division between theories working closer to a radical orientation and those working closer to a social regulation framing. The theoretical framings are updated from Burrell and Morgan to account for changes identified by Gioia and Pitre (1990) and renaming by Sovacool and Hess $(2017,735)$. The axis is framed on the bottom and top by two different perspectives. The bottom is the 'sociology of regulation' which provides "explanations of society in terms which emphasise its underlying unity and cohesiveness" (Burrell and Morgan 1979, 17). The top is the 'sociology of radical change' which explains "deep-seated structural conflict, modes of domination and structural contradiction ... [which are concerned with] emancipation from the structures which limit and stunt this potential for development" with a focus on material and psychic deprivation (Burrell and Morgan 1979, 17). Here, society and politicians interact to create a socially based energy system. This system aligns with the subjective social construction of reality (left). At the same time, a more positivist objective view of events and a realist interpretation characterizes the physical energy system (right) (discussed next).

The strengths of these individual theories within their quadrants are an acknowledgment of the diversity of assumptions underpinning how people perceive order or conflict in the world - and perceptions of the energy system. There is a structure that organizes perceptions of the energy system. There is a radical perspective that perceives conflict fostering change, and the other is social cohesion, which regulates transitions. Both influence technology development in different ways. The socio-techno imaginaries and MLP assume levels of social cohesion in the energy system. In contrast, the literature on social practice theory and geopolitics of cultures assumes higher levels of conflict values and diverging interests fomenting change in the energy system. More specifically, there is graduated scale of perspectives on the energy system. Each framework can lie closer or further from a sociology-of-regulation or a sociology-of-radical change. These frames help understand, through frameworks, how systemic change and cultural influence transform the energy system. 


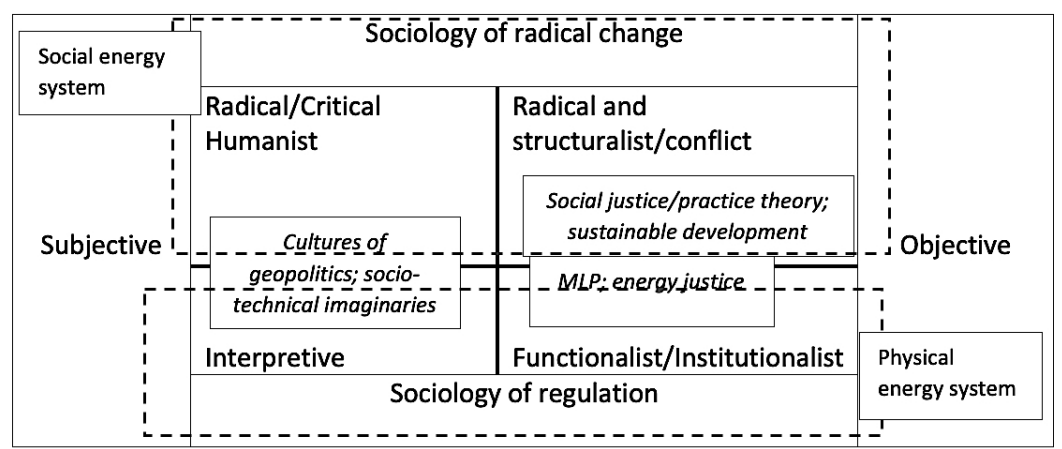

Source: Modified from Burrell and Morgan (1979, 23).

Figure 1.2 Paradigms of social theory analysis within the energy transitions literature

\subsection{PHYSICAL AND SOCIAL ENERGY SYSTEMS}

Describing the energy system needs to advance beyond a simple 'subjective' and 'objective' view. This is complicated by the multi-paradigm concept of 'culture,' which spans each of the paradigms. Therefore, a new conceptual alignment that views the lines of a 'sociology of regulation' or 'radical interpretation' enables established theories to apply to a 'physical' or 'social' energy system. This differentiation of perspectives of the energy system results in highlighting the unique qualities in each paradigm. The bottom-half of Figure 1.2 outlines the shared assumption of social cohesion and social regulation (sociology of regulation); this is observable in the physical form of the energy system. The cohesion provides the glue to organize through social or state institutions, thereby creating an energy system with established social practices observable through norms, values, regulations, or legislation. In contrast, the top half of the diagram highlights the social construct of the energy system (sociology of radical change), which assumes socio-political relations create conflict within the energy system. These two energy systems are explained next.

The physical energy system (representing a functionalist/institutionalist objective perspective, see Figure 1.2), is composed of the observable physical components, such as power plants, pipelines or automobiles. In contrast, for the interpretivist paradigm, the physical construction is interpreted for what it means or represents. The physical system impacts the reality of the everyday experience, with the assumption that society is "cohesive, ordered 
and integrated" (Burrell and Morgan 1979, 17, 31), with society experiencing life through subjective experiences. The physical energy system is based on social cohesion and the ability to observe energy use in the landscape or infrastructure.

The social energy system assumes that the structure of the energy system creates relational conflicts. This approach is best explained by contrasting the definition of 'institution' and contrasting what are institutions through the two paradigms of Sociology of Regulation and that of Radical Change. First, through the regulation perspective (bottom half of Figure 1.2) institutions simply exist as objects in the natural world. They are viewed as independent of societal conflict because they are created and organized by the state. This view is "concerned with providing an explanation of the status quo, social order, consensus, social integration" of stability within institutions (Burrell and Morgan 1979, 27). It is a favorable view of the state. Second, in a more flexible radical interpretation (top half of Figure 1.2) the energy system is a social construct with institutions representing structured (historical) social practices recognized - and respected - by the majority of society (Giddens 1982, 9-10) thereby enabling their continual existence. More specifically, the 'system' is "reproduced relations between actors or collectivities, organized as regular social practices" (Giddens 1982, 35), with structured social practices forming institutions. In this critical interpretation of how institutions work, the socially constructed institutions hold deep power relations. The danger here is that the relations translate into dominant and subjugated relations (often mediated by socio-political and economic relations). For example, the sociology of radical change seeks to explain, "deep-seated structural conflict, modes of domination and structural contradiction" (Burrell and Morgan 1979, 17). The social energy system requires a critical approach to unpack contested power relations.

The social and physical energy systems are explored through the frameworks of energy justice and a geopolitics of cultures. Figure 1.3 provides a visual representation of the interlinkage of the main paradigms around energy cultures. The framing demonstrates the subjective and objective views of the energy system. Energy justice and geopolitics sit opposite each other, the latter representing an 'objective' view of justice (Heffron, McCauley, and Sovacool 2015), while the former represents a subjective world view of diplomacy (Toal and Agnew 2002, 456). Each provides an effective means to formulate international and domestic events through a cultural prism. The cultural landscape of a country affects relations between countries. The question must be asked, to understand state relations: "How does the geopolitical culture of a state spatialize world politics and fill it with certain defining dramas and dangers, friends and enemies?" (Toal and Agnew 2002, 457). The study of geopolitics involving the energy sector exposes deeper power relations within an energy system and embedded cultural practices. 


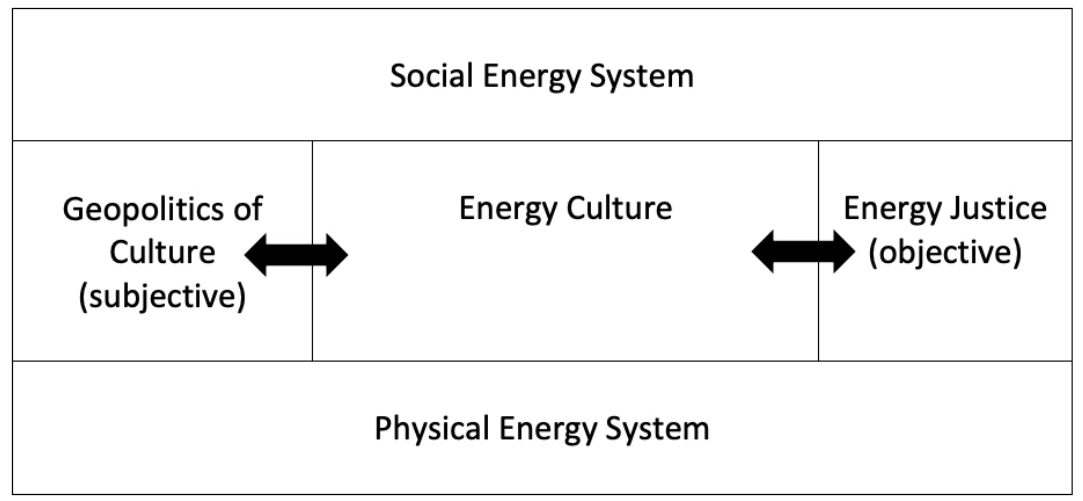

Source: Author.

Figure 1.3 Conceptual components of energy cultures

\subsection{ENERGY JUSTICE AND GEOPOLITICS}

Geopolitics and energy justice work through the state by operationalizing and institutionalizing relations within the energy system, thereby creating an energy culture. Therefore, it is important to understand who is creating culture and their motives. The culture of a society informs how the political-economic system organizes the energy system to meet social, political, or economic objectives. This means culture, with the power to influence and interpret a just energy system, along with the policy environment, contains both economic and political value. Thereby, controlling or influencing an energy culture delivers social, economic, and political benefits to those shaping an energy culture.

Just as Mitchell asks, "who produces culture and why," Jenkins et al. ask the question of "justice for whom" and "justice by whom" (Jenkins, McCauley, and Warren 2017, 837), thereby seeking out who is responsible for creating a culture and delivering equity and fairness in the energy system. This is an objective perspective of a geopolitics of culture. In contrast, 'soft power' is a subjective view, which reflects internal cultures. This domestic culture can appeal to other nation-states prompting cultural alignment of states (J. S. Nye Jr. 2004; Toal and Agnew 2002). Together, energy justice and a geopolitics of culture represent tools to assess the contiguous cultural alignment of states from domestic energy systems to international energy systems. Comparing and contrasting state cultural alignment, in energy systems, fosters a deeper understanding of cultural perceptions of justice and security. The next two sections 
delve deeper into how each of these conceptual framings informs a deeper understanding of energy culture.

\subsubsection{Energy justice}

Energy justice is framed by core notions of the 'three As,' which is the availability of specific forms of energy, access to energy services and the affordability of energy. These 'As' also include distribution of environmental risks and fair treatment in accessing the benefits of energy services and resources (Jenkins, Sovacool, and McCauley 2018, 67). The state in developed countries is important for organizing the marketplace, and creating institutions to monitor and shape the rules and regulations to provide an equitable energy system. Nonetheless, there are challenges in delivering a just energy system.

Explaining efforts by the state to meet social commitments draws on the strength of energy justice (Hiteva and Sovacool 2017, 632). The diversity of a country's society requires the state to steer energy transitions while also accounting for social diversity, norms, values, and ensuring long-term system stability. "Failure to adequately engage with questions of justice throughout the transition process is dangerous. It may lead to aggravated poverty, entrenched gender bias, and non-participation as outcomes or by-products of 'blinkered' decision-making" (Jenkins, Sovacool, and McCauley 2018, 67). Energy justice, through the three 'As,' provides a top-down perspective to explain and explore normative cultural understandings within an energy system. In contrast, a bottom-up perspective is provided by recognition and restorative justice, these 'two Rs' acknowledge local perceptions of justice. Space and scale emerge as lenses to perceive types of injustices within the energy system and highlighting inherent tensions between a universal and particular application of justice.

The spatial interpretation of energy justice rests on the placement of the framework in the spatial justice literature (Harvey 1996; Massey 1973; Gibson-Graham 1996). Scale provides the framing; for example, it brings in cosmopolitan justice that perceives a universal human right to access energy resources and services. This spatial and scale approach embraces consideration by Harvey of spatial injustices (Harvey 1996) and highly localized interpretations of justice that differ when juxtaposed against a universal cosmopolitan framing of justice (Sovacool and Dworkin 2014). Energy justice, as a conceptual tool, enables a multi-scalar perspective that focuses on different sections of the energy system - used as units of analysis (see Jenkins 2018, 119) - to account for both local and global processes that lead to engagement with the energy sector by a range of actors. Two defining camps of justice emerge, 
these are 'universal' and 'particular' energy justice (see LaBelle 2017c) with the following attributes:

1. Universal energy justice holds to values reliant on historical judicial and philosophical groundings that are based in (a) procedural justice, (b) distributional justice, and (c) cosmopolitan justice (for a discussion of these forms see Heffron et al. (2015), Jenkins et al. (2016), Sovacool and Dworkin (2015)) (cited from LaBelle 2017c).

2. Particular energy justice is a nuanced accounting of localized issues and interpretations of social, political, and economic actions affecting access to energy resources and services. Recognition justice, which provides cultural and political representation of groups with distinguishing features such as social, ethnic, and gender differences; freedom from distortion, devaluation, degradation, and physical threats by other groups (Heffron and McCauley 2014, p. 436) (cited from LaBelle 2017c).

Bridging universal notions of justice, such as the basic right to energy services along with localized (particular) interpretations of justice stems from situatedness and positionality of individuals in society (Harvey 1996, 342). The historical and geographical representation of the state is expressed through national cultures and state institutions (Harvey 1996, 351). These are localized interpretations and are particular to a location and informed by scalar relations. Building a sense of a 'just energy system' constitutes a range of cultural, institutional, and historical experiences and structures which are designed to deliver energy services to match social expectations within a nation-state (particular) and through global connections and awareness (universal).

The universal notion is demonstrated by Sovacool et al., who develop a "transboundary nature of injustice" (Sovacool, Sidortsov, and Jones 2013a, 29); this emphasizes universal burden-sharing by a global citizenry. Universal energy justice provides "global energy system that fairly disseminates both the benefits and costs of energy services and one that has representative and impartial energy decision-making" (Sovacool and Dworkin 2015, 436). Access to energy services is a universal human right of all citizens (United Nations General Assembly 1948). The justification for this is that access to energy services enables access to other services such as health care, education, and employment (Sovacool, Sidortsov, and Jones 2013a, 25-6). Therefore, the state is central in ensuring access to energy services (for further explanation, see LaBelle 2017c). There are three universal justices: procedural, distributional, and cosmopolitan. Each of these is reliant on institutions to assist implementation (see, Table 1.2 for definition). Additionally, the second perspective, 
the 'particular energy justice,' stems from how energy services are perceived and delivered locally.

The particular approach is defined as a nuanced accounting of localized issues and interpretations of social, political and economic actions affecting access to energy resources and services. It gives voice to grievances even within seemingly universally just energy systems. (LaBelle 2017d, 616)

Cultural and political representation are heavily present in the concept of energy justice and rest within the institutions of the state. Cultural features such as gender and ethnic divisions are highlighted within the provision of energy services enabling local stories to highlight differences in access to energy services (Schlosberg 2004, 534-5; Fuller and McCauley 2016, 2). Recognition and restorative justice lie within the particular energy justice grouping; however, for restorative justice to occur, there first must be a recognition of both groups and the injustices, therefore the discussion going forward is largely on recognition justice. Table 1.2 outlines the different types of energy justice. Splitting of types of justices enables a more nuanced accounting of how societies create perceptions of justice.

There is tension within the definitions of energy justice. For example, particular energy justice does not exclude universal notions of a working legal system but envisions a particularized application to the legal norms. "Decisions and actions will be evaluated less according to whether they are right or just than according to their legal validity, that is, whether they are consistent with the rules and follow the appropriate procedures" (Young 1990, 77). This objective view of the legal system, therefore, also must conform to long-established legal norms to ensure fair representation and freedom from political interference. There is an inherent tension between a global (universal) interpretation and local (particular) interpretation of delivering a just energy transition. Fairness applies in both a universal and a local justice interpretation, meaning alignment between the two approaches is a necessary attempt to ensure a fair process. Nonetheless, there is failure to provide a just energy system. Justice is always in the process of becoming as cultures shift. The processes of pursuing a universal form of justice differ from any final form of universal justice: "Utopianism of process looks radically different from a Utopianism of form" (Harvey 1996, 333, cited by LaBelle 2017c). That is, there is no end-state. Just as culture continues to evolve, so does the definition of justice within the broad parameters of energy justice. 


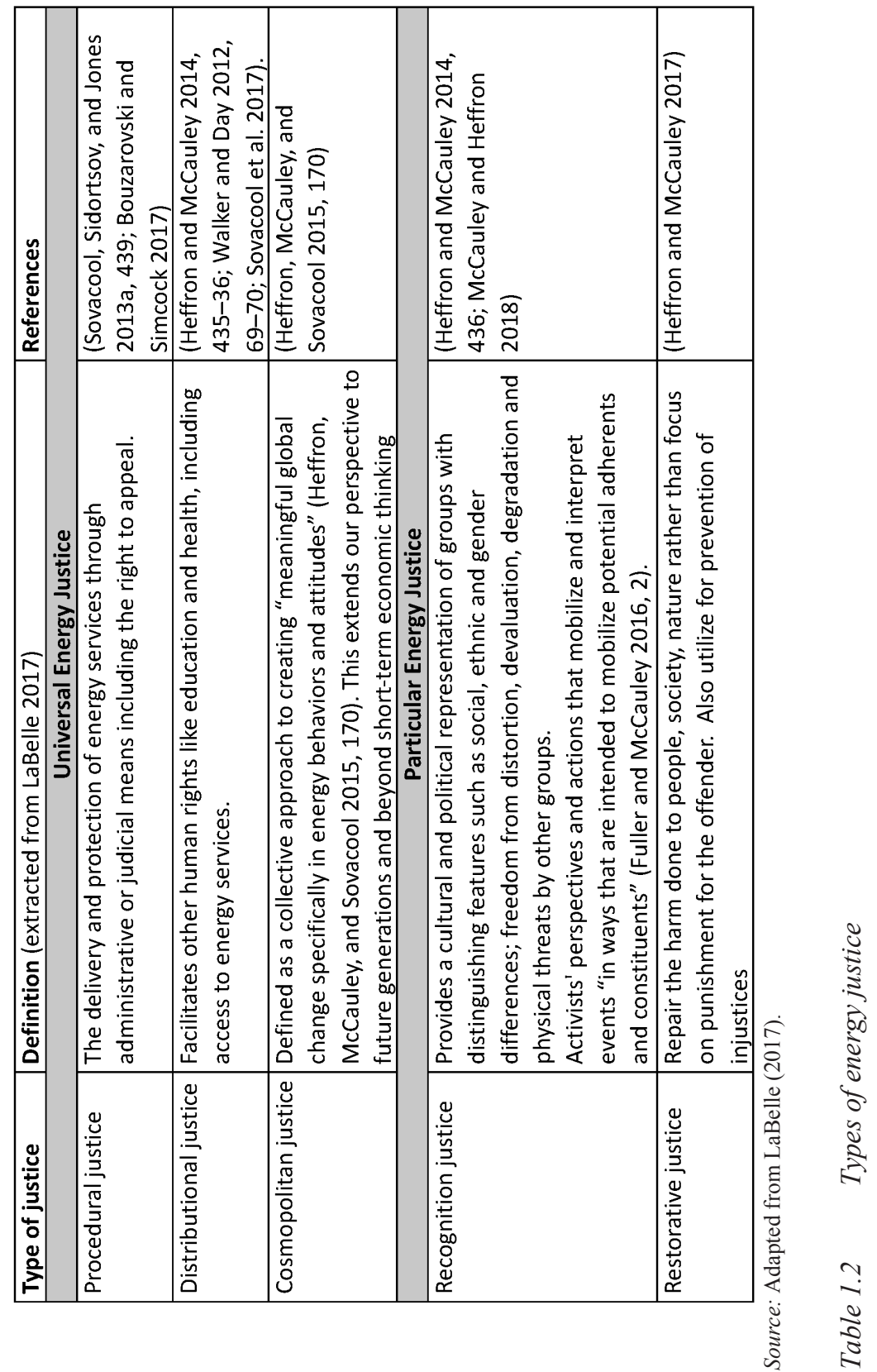




\subsubsection{Geopolitics of culture and soft power}

The extension of justice, reflecting both domestic cultural practices and universal concepts, parallels a geopolitical approach which incorporates domestic cultural reflections into international action. The discussion centers on 'a geopolitics of culture' which observes cultural traditions in nation-states and interprets international actions through a cultural reflection (Toal and Agnew 2002). This approach moves beyond 'discursive geopolitics,' which draws on a traditional geographic perception of "socio-cultural resources" (O Tuathail and Agnew 1992, 193) describing power ideologies of imperialism on the landscape and through state (military) actions (Mackinder 2004; Bassin 1987). Rather, through this revised framing, the identity of nation-states is understood to help expose power alignments through cultural practices on the landscape and implementing policy goals. This geographic gaze produces a conceptual 'power continuum' extending from soft to hard power. Geopolitics of culture describes domestic cultural interactions in the international geopolitical arena.

Within a broader alignment of culture and geopolitics, an example is provided by Hadfield who utilizes a 'strategic culture' lens, which identifies culture as governing EU-Russia relations through "national cultures or regional requirements, in which cardinal beliefs are perceived to be at odds with other viewpoints, prevent cooperation and prompting belligerence, even aggression" (Hadfield 2016, 781). The essential point is culture influences international relations, it formulates perspectives on areas of cooperation or disagreement, thereby providing the context of actions with other international actors. From this point, the question can be proposed: How does culture influence spatial relations and provide labels of friends or enemies? (Toal and Agnew 2002, 457). The study of geopolitical cultures seeks to understand domestic discourse and debates about nation-state identity and international relations drawing from a territorial position (Toal and Agnew 2002, 457). The geographic gaze shifts from looking at the Imperial Powers fight over territory, and instead looks at the clash of cultures and the expression of power relations occurring both domestically and internationally.

Culture has an important role expressing soft power in geopolitics. According to Nye (2011), soft power relies on three basic resources: culture and how attractive it is to others; expression and practice of political values; and foreign policy perceived as legitimate and holding moral authority (the last two categories also connect with perceptions of justice). Making or breaking the possession of soft power is behavior around attraction of a state and whether it can wield this power to influence outcomes. Socially constructed, soft power is hard to use and can be lost (Nye 2011, 83-4). Therefore, tension exists between those wielding softer and harder approaches to geopolitical power relations. This tension underscores the considerable gray area between 
hard and soft, which can include using military and economic resources to exert power (Goldthau and Sitter 2015).

The study of geopolitical cultures benefits from this soft/hard power continuum and power of (cultural) attraction. Soft power shapes nation-states' identities and international alignment within a less militaristic state alignment. The diversity of culture flourishes in another gray area and is exemplified by understanding culture as attractive for its knowledge and values, which motivates participating in a culture.

Culture can be an important power resource. "Culture" is the pattern of social behaviors by which groups transmit knowledge and values, and it exists at multiple levels. Some aspects of human culture are universal, some are national, and others are particular to social classes or small groups. Culture is never static, and different cultures interact in different ways. (Nye 2011, 84)

Rather than viewing culture as only soft power, Goldthau and Sitter propose the existence of 'soft power with a hard edge,' to describe the governance and stability of the EU's Single Energy Market (SEM) (Goldthau and Sitter 2015). The authors describe the attractiveness of the EU's energy market as a means to influence third-party states to conform to the market and moral conditions inherent in the EU's energy system. The EU's internal rules are accepted by external actors (such as Gazprom) for the chance to 'come and play' in the EU's Single Energy Market (SEM). In this scenario of soft power, the EU exerts power by having attractive values, institutions, and (liberal) market ideology operating in an attractive market environment (Goldthau and Sitter 2015, 8).

Geopolitics of culture provides a means to understand that the internal culture of a nation-state holds international ramifications in alignment with friends and enemies. This geopolitical culture is not devoid of values and norms; rather it reflects these while asserting the power of the state into the international arena of states and organizations. Geopolitics of culture, therefore, enables both an alignment of states and assertion of power stemming from traditions and historical relations. Moral authority and social practices are bound up in soft-powers, serving to attract rather than force a spatial alignment of allies. This embeddedness of justice aligns with the normative framing of energy justice, reflecting structured values and norms of nation-states and the provision of energy resources and services. 


\subsection{ENERGY CULTURES: FROM EMPIRICAL TO THEORETICAL}

The right to access energy resources and services as a universal human right, combined with the fundamental transformation of the fossil fuel-based energy system, requires re-engaging with the concept of energy culture. The confluence of the energy transition reminiscent of the second industrial revolution experienced by Ostwald and his contemporaries was a time of rapid social and technological transformation, including the development of academic disciplines, like geography and sociology. They attempted to capture and explain both the lived cultural experiences and transformations of the landscape. The site of combustion in the Anthropocene (Dalby 2018) is also the site of power relations. These relationships flow through the physical infrastructure and are visible on the landscape and in the environment. The development of energy culture matches the call by Nye, who states, "More research needs to be done on the connection between culture and power behavior" $(2011,84)$. The concept of energy culture re-emerges in this transformative period to capture the power relations in culture, its use and interpretations of justice to inhibit or speed up the energy transition.

An energy cultures framework provides a conceptual means to interpret and explain how and why each country orientates and changes its energy system. This chapter set out to review and reframe the production of energy culture, including a critical critique to operationalize it through cultural geography, geopolitics, and energy justice. This chapter briefly captures these overlaps and enables a structured paradigm formulation exposing cultural processes influencing national energy systems. The following three chapters represent case studies that highlight different types of energy cultures and efforts to produce just energy systems while also expressing geopolitical cultures.

The strength of the energy cultures framework is in erasing the binaries of demand/supply and domestic/international. This also results in limitations. For example, it does not replace the reviewed conceptual framings used either in current energy cultures literature or energy transitions theories. The state, in this framing of energy cultures, is the central organizing structure. Therefore, decentralized and citizen-led initiatives may reflect the failure of the state, but the organizing structure will rely more on a social informal structure to shape and build an energy culture. Power relations will occur at the community level, in the absence of a powerful state. A critical approach to energy cultures seeks to uncover these hidden power relations; in this effort, insufficient attention will be given to the broader impact of a culture on the landscape or in the field of technology. Finally, more granular interpretations of culture and social 
conformity or contestation may be missed due to the joint demand/supply side focus.

\begin{tabular}{|c|c|c|c|c|c|}
\hline Empirical & Scale organization & $\begin{array}{c}\text { Spatial } \\
\text { organization }\end{array}$ & $\begin{array}{c}\text { Ontological } \\
\text { framing }\end{array}$ & $\begin{array}{l}\text { Epistemological } \\
\text { framing }\end{array}$ & Energy culture \\
\hline Case study framing & $\begin{array}{l}\text { Shallow Structure } \\
\text { Level of struggle } \\
\text { lallow Structure }\end{array}$ & $\begin{array}{l}\text { Landscape and } \\
\text { materiality }\end{array}$ & $\begin{array}{l}\text { Expressed social } \\
\text { reality in discourse } \\
\text { and narratives }\end{array}$ & $\begin{array}{c}\begin{array}{c}\text { Norms, laws } \\
\text { expressed through } \\
\text { institutions and } \\
\text { actions }\end{array}\end{array}$ & $\begin{array}{l}\text { What is the } \\
\text { representation of } \\
\text { injustice? }\end{array}$ \\
\hline $\begin{array}{l}\text { Level 1, Identify: } \\
\text { Manifestation of } \\
\text { energy culture in } \\
\text { artifacts or practice }\end{array}$ & $\begin{array}{c}\text { Explicit } \\
\text { representation } \\
\text { (surface level) }\end{array}$ & $\begin{array}{l}\text { Social practices } \\
\text { and materiality } \\
\text { Intermediate } \\
\text { Structure }\end{array}$ & $\begin{array}{l}\quad \text { Intermediate } \\
\quad \text { Structure } \\
\text { Paradigms: } \\
\text { Interpretivist } \\
\text { framing }\end{array}$ & $\begin{array}{c}\text { Scale: Particular } \\
\text { (local) social justice } \\
\text { framing }\end{array}$ & $\begin{array}{l}\text { How does culture } \\
\text { represent } \\
\text { injustice and } \\
\text { power? }\end{array}$ \\
\hline \multirow[b]{2}{*}{ Cultural Milieu } & $\begin{array}{c}\text { Internal/domestif } \\
\text { ethics }\end{array}$ & $\begin{array}{l}\text { Equity in access } \\
\text { and services }\end{array}$ & ENERGY JUSTICE & Ethical/injustice & $\begin{array}{c}\text { What are the } \\
\text { power relations? }\end{array}$ \\
\hline & $\begin{array}{c}\text { Externa/ \& } \\
\text { international power } \\
\text { relations }\end{array}$ & $\begin{array}{c}\text { Use of networks, } \\
\text { technologies and } \\
\text { resources }\end{array}$ & GEOPOLITICS & trial justice & $\begin{array}{l}\text { How are relations } \\
\text { socially } \\
\text { transformative? }\end{array}$ \\
\hline $\begin{array}{c}\text { Level 2, } \\
\text { Constructions: } \\
\text { Social; physical; } \\
\text { individual; gender; } \\
\text { economic; political }\end{array}$ & $\begin{array}{l}\text { (mplicit } \\
\text { representation } \\
\text { (deep structure) }\end{array}$ & $\begin{array}{l}\text { Socio-economic } \\
\text { and political- } \\
\text { economic }\end{array}$ & $\begin{array}{l}\text { Paradigms: Radical } \\
\text { Subjective framing }\end{array}$ & $\begin{array}{l}\text { Scale: Universal } \\
\text { social justice } \\
\text { framing } \\
\begin{array}{c}\text { Deep } \\
\text { Structure }\end{array}\end{array}$ & $\begin{array}{l}\text { How do relations } \\
\text { create energy } \\
\text { culture? }\end{array}$ \\
\hline
\end{tabular}

Source: Author's own conceptualization.

Figure 1.4 Levels of abstraction to operationalization of radical energy culture

Figure 1.4 provides a stepped perspective of how energy culture is theoretically and geographically constructed. The categories in the first column build the empirical framing at both the surface level, in terms of how energy cultures are expressed in the everyday or in landscapes (level 1: artifacts and practices), while level 2 is representative of deeper processes and relations intertwined with political-economic and social constructions. The 'cultural milieu' is descriptive of the area of interaction of social relations where culture is created and influenced by both the operation and construction of institutions and infrastructure. The columns listing 'space' and 'scale' structure the organization of specific levels and spaces of noticeable representation of energy culture. The use of ontological and epistemological framing influences the perceptions and scale of analysis of framing of social processes (epistemological) which are explained through the theories and paradigms (ontological). This leads to the exposure of the relations that create radical energy culture, in the last column. The process is framed at different levels through the exposure of the structures that build into the question, 'How do relations create energy cultures?' 
There are different levels of analysis that frame the energy system in different ways. It is necessary to work through these to understand both the representation of culture and how it is created. There are three levels to the energy cultures framework. The first, the 'shallow structure' draws from the everyday, while the second, the 'intermediate structure' provides an explanatory value of observations of both deep and shallow structures. The third level, the 'deep structure,' arrives at an answer of how relations create energy culture. Energy cultures rely on the spatial-scale and the ontological-epistemological scaffolding to expose relations and social processes within an energy system.

\subsection{CASE STUDIES OF ENERGY CULTURES}

One of the vestiges of the Communist period dominated by the USSR is the built energy infrastructure in Eastern Europe. Oil and gas pipelines, along with nuclear power plants and large concrete panel houses are the most prominent symbols of the energy resources, production, and consumption which continue to function today. The geographic routes and supply lines along with technical expertise unified the Eastern Bloc countries to Moscow's scientific and technical expertise. Each of these sources of power delivered low-cost energy to households and factories. The fall of the Berlin Wall in 1989 was a symbol of deep changes in all the Soviet Union's satellites in Eastern Europe. Gaining membership into the European Union on May 1, 2004, for many of these countries, represents even deeper changes. The base of this economic change was an energy system that was forced to straddle two economic and political systems. As the chapters explore, each former Communist country developed a unique approach to assert its own domestic energy culture with the new geopolitical alignment. Three case studies of Lithuania, Hungary, and Poland describe in detail how different energy cultures express different geopolitical and energy justice approaches.

The geopolitics of energy are displayed in the vast sums for infrastructure development. The European Union is dedicating 100 billion EUR in the 2021-7 funding cycle to Member States to create a 'Just Transition Mechanism,' while Russia completes its North Stream Two pipeline through the Baltic Sea and its Turk Stream in Europe's southern gas corridor for about half this amount. Two competing projects, one focused on 'green' energy solutions and the other sending a fossil fuel, demonstrate the underlining values and strategic infrastructure projects within a clash of energy cultures. The geopolitical alignment of Eastern European countries is wrapped up in their use of resources and technologies, with the cost borne by social justice issues and geopolitical conditions. Infrastructure projects and the conversion technologies along with the built electricity and gas networks represent the international alignment of states along with the consumption habits of citizens. The energy cultures of 
Eastern Europe are tied to the geopolitical power centers to the east and west. Chapter 2 describes these in more detail.

The clash of culture emerges even within the international orientation chosen by a country. In Hungary, the expression of a 'Christian green policy' is compared to a Brussels bureaucratic approach (Varga 2020); in Poland, the defense of Polish coal is a defense for Polish technology (Sitarski 2019); while Lithuania's EU membership meant shutting down Lithuania's Soviet nuclear power plant, thereby "killing the golden goose" (personal communication, Straupaite 2018). EU membership transformed Eastern Europe's energy system and created a clash of energy cultures, because technologies and resources reflect deeper social, economic, and political relations. The push by EU institutions to go 'greener' pushes up against Eastern Europe's Communist energy system of inefficient consumption. It is important to consider that energy systems hold explicit and implicit socio-political relations. The reason for the clash between East and West perspectives are the authoritative power relations within energy cultures, such as the EU 'forcing' Member States to change their technologies and resources. The transformation in turn affects the relationship between society and politicians.

Relations within the energy system are contested at a range of scales. There is also contestation over what creates a just energy system. Is it only a sustainable and green energy system? Or is it one with low prices where consumers can afford to heat their homes? Energy justice becomes a contested phrase depending on the local (particular) interpretation. At the heart of the EU's 'green and just' project is the assumption there is a definable 'just energy transition' (European Commission 2020). As will be discussed in the next chapter, the cost of the transition is a serious concern for Eastern Europeans. Understanding the injustices within the current energy systems highlights domestic political social relations and policy choices shaping national energy cultures. Lithuania, as Chapter 3 discusses, chose to diversify away from the Soviet-era energy system and embrace EU competition rules. The price of energy for households is a fundamental problem in both Hungary and Poland. For example, in Hungary, as Chapter 4 describes, each year around 200 people die of hypothermia, half in unheated homes (personal communication, Simo 2018). This underscores the cost of energy as an essential social and political issue. Poland, described in Chapter 5, also grapples with high rates of energy poverty and uses cheap coal to ensure adequate heating, but with a trade-off of dangerous levels of air pollution. Polish cities and villages have some of the most dangerous levels of air pollution emanating from coal furnaces and power plants; with 36 Polish cities in the top 50 most polluted cities in Europe (Radio Poland 2018). The case studies provide the chance to understand both geopolitical orientations of the energy system as well as society's request for a just, affordable, and clean energy system. 


\subsection{CONCLUSION: THE CLASH OF ENERGY CULTURES}

Culture is not a benign representation of a nation or social practices (Mitchell 2000), but rather culture actively transforms the energy systems through (power) relations. Energy culture, as a concept, exposes the reasons and relations within the transformation. The production of energy culture is expressed in the explicit in the physical form seen in resource extraction, combustion technologies, and networks. The implicit relations in energy cultures are perceptible in social and power relations within the energy system. The production of geographic inequality and flows taps into the bounding out of energy justice (Jenkins 2018, 120) at different scales of the energy system. These arrangements are reflective of "underlying structural mechanisms that produce spatial inequality" (Bouzarovski and Simcock 2017, 645). The explicit demonstration of energy culture on the landscape provides a visual representation of inequity and unjust systemic constructions of the political economy.

Finding the value in energy cultures requires a stepped theoretical approach, which moves from the surface-level representation of culture to expressions of culture that structure power relations and the political economy of society within an energy system. Chapter 6 provides a more in-depth understanding of energy cultures as a theoretical contribution which provides a radical interpretation of spatial justice that emphasizes the geographic "dimensions of inequality and inequity" (Bouzarovski and Simcock 2017, 640). Applying the term, 'culture' enables a multidimensional approach to assist understanding the diverse perspectives that influence the operation of the energy system.

Chapter 7 builds the interconnection between energy justice and geopolitics within the energy system. The cultural significance for geopolitics rests with the boundaries of the nation-state and how internal social processes influence external relationships. Domestic cultural interpretations of actions influence interactions between states. Access to resources and energy services also differ within and between countries. This inequality is raising moral and ethical questions of how state institutions and society ensure fair and equal access; access to energy resources and services has been an established universal human right since 1948 (United Nations General Assembly 1948). Just as nation-states have sovereign rights in the international realm, citizens have the basic right to energy services. This reinforces other "basic goods to which human beings are entitled, like welfare, security, health care, education, and the right to employment" (Sovacool, Sidortsov, and Jones 2013b, 25-6), thereby underscoring the importance of the state in the provision of energy resources and services and creating tension between a universal notion of access and local interpretations of sufficient access. 
The state is the container of a government mediated energy system. Geopolitics and energy justice work through the state by operationalizing and institutionalizing relations that also create a culture of energy. Therefore, it is essential to understand who is shaping culture and their motives. The culture of a society informs how the political-economic system organizes the energy system to meet social, political, and economic objectives. Culture has the power to influence and develop a just energy system. Controlling or changing an energy culture delivers social, economic, and political benefits. The question is, 'Who benefits from an energy culture?'

Just as Mitchell asks, 'who produces culture and why', Jenkins et al. raise the issue of "justice for whom" and "justice by whom" (Jenkins, McCauley, and Warren 2017, 837), thereby seeking who is responsible for creating culture and delivering equity and fairness in the energy system. Extending energy cultures into a global framework is the geopolitics of culture, which expresses soft power. The expression of domestic cultures works by appealing to other nation-states, prompting a cultural alignment of states (Nye Jr. 2004; Toal and Agnew 2002). This expresses a subjective arrangement of states. Energy justice and a geopolitics of culture represent tools to assess the alignment of states. Chapter 6 compares and contrasts these alignments of cultures in energy systems, enabling an understanding of states based on perceptions of justice and security.

Finally, Chapter 8 provides a broader view on the "sciences of culture" (Weber, Mikkelsen, and Schwartz 1984, 51) which have shifted over the last century. The chapter explores the importance of the energy system, and relations within it, which have grown more substantial to meet social and economic needs in the period of transition away from fossil fuels. There is a need for a fundamental reorientation of both the social, political, and economic systems to build a sustainable energy transition. At the center of this transformation are cultural practices within the energy system. It is these practices and the relations that create energy cultures that this book addresses. Chapter 8 concludes this book with a summary of how the concept of energy cultures can meet the challenges in this transition. Exposing the power relations, and both the explicit and implicit expressions of energy cultures, identifies where injustice prevents the development of a just energy system. Politicians hold a moral and political responsibility to honor both the social contract and regulatory compact in modern developed energy systems. The basis of the modern democratic state with a centralized energy system requires politicians to pursue a just energy transition. 